\title{
Chemical processes and sustainability
}

\author{
John A. Glaser
}

Published online: 30 October 2012

(C) Springer-Verlag Berlin Heidelberg (outside the USA) 2012

In a pair of companion papers, sustainability indicators for chemical processes are explored for their potential contributions to the further understanding of sustainability and continuing needs for supporting data. Design modifications of existing and new chemical process technology are required by the chemical industry's response to meet society's needs for chemicals derived from ecological materials. The use of ecological services by new processes must be scrutinized through complete sustainability assessment to enable decision makers in the selection of environmentally suitable technology. Sustainability indicators are analyzed through taxonomic classification in accordance with the proposed directions of GREENSCOPE (Gauging Reaction Effectiveness for the Environmental Sustainability of Chemistries with a multi-Objective Process Evaluator) methodology. The first paper offers a taxonomic analysis of sustainability indicators and inventories them into several different categories. There are 66 indicators identified in the category of environmental indicators for sustainable assessment of chemical processes. There are 26 efficiency, 33 economic, and 15 energy indicators which were also identified for evaluation. The obvious issue with this large inventory and its testing is the availability of the requisite data. From this analysis, we can expect to see future research provide testing results in

J. A. Glaser $(\bowtie)$

National Risk Management Research Laboratory, US

Environmental Protection Agency, 26 W King Dr,

Cincinnati, OH 45268, USA

e-mail: Glaser.John@epa.gov database form to permit the evaluation of chemical process sustainability. The data needs are analyzed in detail in the second paper. The structured methodology for taxonomic analysis of sustainable indicator evaluation permits the clear identification of process sustainability.

Ind Chem Res 2012, 51, 2309-2328; 2329-2353.

\section{One-pot heterogeneous catalysis}

A 61 page review systematically details how chemicals can be synthesized in a one-pot scenario by heterogeneous catalysis. Multistep sequential processes are catalyzed by single-site acid, base, and metal catalysis. Greater complexity can be brought to the reaction design by combinations of conditions such as differentiated bifunctional acid-metal, basic-metal bifunctional, bi-and multimetallic, acid-base bifunctional, and acid-base-metal trifunctional catalysis. The attractiveness of one-pot synthetic solutions can assist the search for cleaner, safer, and environmentally friendly technologies. The multiple catalytic events involved in such one-pot syntheses can proceed to reduce operational cost and energy use through beneficial changes to separation and purification components. Lower $E$-factors, improved atom economy, and required consumption of energy and materials may be realized with the implementation of one-pot synthetic strategies. One example of solid-acid site conditions is depicted in the following scheme where double bond isomerization is followed by lactonization. The products of this reaction sequence can be found in applications such as solvents, extraction agents, and fine chemicals involved in the synthesis of pharmaceutical and bioactive compounds important to agricultural pest control. 
<smiles>C=CCCCCC(=O)O</smiles>

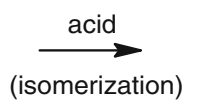<smiles>CC/C=C/CCC(=O)O</smiles>

\section{Methyl vinyl ketone}

Friedel Craft conditions
Another example can be seen in the following scheme detailing synthesis of fragrance chemical, "raspberry scent fragrance." The commercial route shows the problems of complexity of side products leading to the separation and purification difficulties and loss of atom efficiency. A multistep sequential process on a single-site basic catalyst follows with a remarkable change in product composition<smiles>CCCC1CCC(=O)O1</smiles>

affected by climate change-induced acidification of oceans. The phenomenon causes fish to migrate to the poles away from the equator. Food shortages are to be expected in island and coastal countries. The Indian Ocean nation, The Maldives, tops the list of countries that depend primarily on seafood. Nations suffering the greatest have done very little to cause climate change.

\section{Commercial route}<smiles>COc1ccccc1</smiles><smiles>COc1ccc(CCC(C)=O)cc1</smiles>

\section{Complex by-products}

One-pot synthesis<smiles>COc1ccc(I)cc1</smiles><smiles>C=CC(C)=O</smiles><smiles>COc1ccc(/C=C/C(C)=O)cc1</smiles>

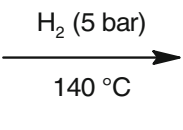<smiles>COc1ccc(CCC(C)=O)cc1</smiles>

$97 \%$ yield

4(4-methoxyphenyl)butan-2-one

(Raspberry scent fragrance)
Chem Rev 2011, 111, 1072-1133

with the yield of raspberry scent fragrance improved to $97 \%$ without complex mixture formation.

\section{High $\mathrm{CO}_{2}$ effects on ocean-based food}

The international organization, OCEANA, devoted to protect the world's oceans, recently released a 14 page informative report, Ocean-Based Food Security Threatened in a High $\mathrm{CO}_{2}$ World that identifies threats to island and coastal countries related to ocean acidification. Marginal fishermen will be affected the greatest. The study shows that ten countries in Asia and Africa will be most
http://oceana.org/sites/default/files/reports/Ocean-Based_ Food_Security_Threatened_in_a_High_CO2_World.pdf.

\section{Process mass intensity}

The American Chemical Society Green Chemistry Institute's Pharmaceutical Roundtable has selected process mass intensity (PMI) as a metric that will permit the evaluation and benchmarking efforts to identify progress leading to sustainable manufacturing technology. This metric is simple and easy to understand which led to its selection over atom economy or E factor. Owing to its focus on waste production, the E factor was not selected. 
Process mass intensity

$$
=\frac{\text { total mass of a process or processs step }(\mathrm{kg})}{\text { mass of product }(\mathrm{kg})}
$$

Applications of PMI are seen to drive pharmaceutical syntheses to greater efficiencies. The paper offers an understanding of the philosophical rationale and scientific merits leading to the selection of PMI. Using information from GlaxoSmithKline (GSK), it was found the PMI correlated well with global warming potential across all development compounds in the GSK portfolio. The Roundtable has used PMI to characterize improvements to the greenness of a process and the related efficiency and innovation encountered in the pharmaceutical and fine
Reduction of these concepts related to the logic of synthetic design was enabled through the expanding prowess of computer science and artificial intelligence. The algorithm was used as the basis for development of a computer program that could produce candidate prospective synthetic strategies for a target molecule. Chemical structures and synthetic instructions were converted to computer code and manipulated digitally according to the specifications of the synthetic algorithm in use to accomplish the computer-based design.

An example of synthetic design is depicted in the following synthetic retrosynthetic scheme for longifolene. The solid arrow in this scheme denotes a disassembling of the target molecule using the logic of connections and functionalization available from established synthetic methodology.

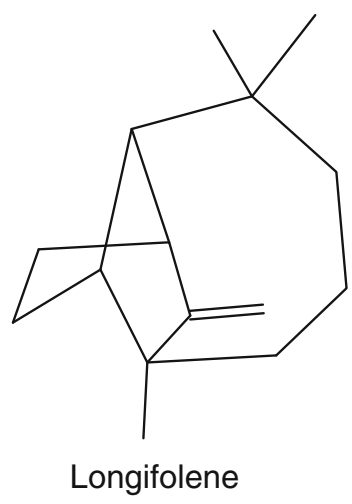

chemical industries. A scientific argument is offered in support of PMI derived from life cycle assessment considerations. PMI cannot provide a complete LCA assessment since many aspects are missing. As a primary mass-based green chemistry metric, PMI appears to be durable and strongly supported by scientific data.

Org Proc Res Dev 2011; 15(4):912-917.

\section{Computer-based chemical synthesis design: a history}

The pharmaceutical and fine chemical industries require tools to enable the synthesis of complex molecules. The synthesis of organic molecules especially ones having complex structure has been accorded the status of art. This specification reflects the application of a general approach to synthetic design relating to applications that are new for each synthesis. In a 1967 essay, an algorithm was presented for the purpose of enabling logical synthetic analysis of molecules targeted for synthesis. This development can be attributed to the earlier manufacture and extension of synthetic strategies to an extensive list of molecules. These milestone syntheses were achieved through a deep specialized understanding of the specific classes of compounds related to a projected synthetic scheme as starting materials or intermediates.

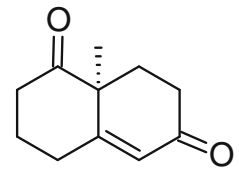

Wieland-Miescher ketone

The use of generalized chemical knowledge and perception of molecular features are basic to the formulation of a synthetic strategy and selection of synthetic transformation components (reactions). For instance, the perception of the target molecule and possible precursors requires consideration of functional groups, ring components of the target, stereochemical specifics, site of molecular equivalence, and symmetry contained in the target. The construction of a synthetic plan requires considerations of the reaction representation which includes reaction transformations and generation of reaction rules.

Some of these terms may sound unfamiliar, but have been used in the development of computer-aided synthetic design. One example of an early success by the computer guided synthetic strategy can be found in the following scheme which depicts the long range halolactonization partial strategy involved in the synthesis of the prostaglandin PGF2 $\alpha$. The Logic and Heuristics Applied to Synthesis Analysis (LHASA) program was used in this endeavor and the partial route depicted exposes the longrange strategic capabilities of LHASA.

This article offers a systematic and sequential understanding of the different computational components required for the full development of current computeraided synthetic design programs. Such in silico technology permits the scrutiny of synthetic planning to aid atom 
<smiles>CCCCC[C@H](O)/C=C/[C@H]1[C@@H](O)C[C@H](O)[C@@H]1CC=O</smiles>

PGF2 $\alpha$

economy, material, and energy conservation and research strategy needs. WIREs Comput Med Sci 2012; 2:79-107.

\section{Energy chemistry}

A Nature Insight issue focused on chemistry and energy is composed of an introductory perspective article and four reviews. The perspective article provides insight into a sustainable energy future by US Department of Energy authors. The paper is divided into the categories of transportation and clean/affordable electricity generation. Within the transportation considerations are internal combustion engines, battery-based electrification, fuel-cell-<smiles>C/C=C(\C)CC/C=C(C)\C=C(/C)CCC(C)C(C)CC(C)CC(C)CCCC(C)CCCC(C)C1CCC(C)CC1</smiles>

Nature 2012; 488: 7411, 292-328 based electrification, natural gas for transportation, and alternative liquid-transportation fuels are scrutinized. The clean and affordable electricity generation considerations solar, wind, decarbonizing fossil-fuel emissions, nuclear, and grid energy storage are examined. The reviews investigate solution-processed photovoltaics, membranebased process, microbial engineering, and algal biofuel production. The metabolic engineering review is focused on the development of advanced biofuels. Pathways for the development of alcohol-, isoprenoid-, fatty-acid-, and polyketide-derived fuels were detailed with the expectations for commercialization and future directions. The following scheme synopsizes some to the pathway development information.

\section{2-Methylpropanol}

Farnesane 


\section{Prospects of de novo spider silk}

The strength properties of spider silk have been widely trumpeted as stronger than steel. The tensile strength of this silk compares favorably with or exceeds the properties of modern high performance synthetic materials. Low molecular weight, biocompatibility, and remarkable mechanical properties of spider silk have attracted the attention of material science.

The basic understanding of the silk expression process within the spider remains unknown. The simple consideration of how the spider's system prevents premature or fatal aggregation processes for the silk polymer as it is expressed through a spinneret is only becoming understood. The fiber formation process involves chemical and physical stimulation to translate changes in the silk and natural aggregation processes. Studies exploring orbweaving spiders such as Araneus diadematus (garden spider) and Latrodectus hesperus (black widow) offer conditions for compositional and structural analysis. A variety of silk types are produced by spiders for different purposes. Each type is produced by one of six silk glands to produce a blend of structural polymers forming a fiber with a defined set of functional properties. This research focused on the function of high conserved domains in the spider silk dragline fiber which adopt a folder conformation in solution and thereby control intermolecular interactions and aggregation of silk molecules. The molecular construction of the silk assembly process is partially uncovered through knowledge of these domains. It is anticipated that this information will be beneficial to the in vitro fiber formation with recombinant silk material. J Pept Sci 2012; $18: 357-365$

\section{Water use survey}

The importance of water to human life and food needs was made to the US population during the 2012 drought conditions affecting the US Farm Belt. A 28 page survey, Drought, Water and Energy: A National Survey of Attitudes, was conducted by the environmental advocacy groups, Civil Society Institute and Environmental Working Group, to identify perceived connections between water supply and energy. People in ten US states were queried about the impact of drought and water diversion to energy production and found to be very concerned about drought, wild fires, and other extreme weather related events in the US. The level of concern was almost evenly perceived across lines of political allegiance in the test group. Safe drinking water shortage was highlighted as the number one concern in the survey across drought stricken states. Higher food, fuel, and utility prices were the major concerns also voiced. The survey showed the interviewed citizens to understand the connection between energy and water better than their representatives. The public recognized the waterenergy connection posed in the use of alternative fuels and favors the development of energy sources that use less water.

http://www.civilsocietyinstitute.org/media/pdfs/081612\% 20CSI\%20drought $\% 20$ energy $\% 20$ survey $\% 20$ findings $\% 20$ FINAL2.pdf.

\section{Surface water threat from natural gas development}

Expanded shale gas production is expected to provide almost half of the US natural gas production by 2035 . As a bridging fuel to renewable energy resources, natural gas offers fewer combustion contaminants in contrast to the use of coal or petroleum. Vast shale reserves are now accessible with the use of horizontal drilling and hydraulic fracturing (hydrofracking or fracturing). Hydrofracking is a drilling technique employing a high-pressure fracturing fluid composed of water and chemical additives to uncover gas deposits. A vertical well is initiated and at a depth suitable to access the gas-bearing strata, the flexible drill bit is navigated in a horizontal direction. Horizontal drilling provides access to a greater volume of strata than by a single vertical well. Depending on the geological strata, well depths of 300-2500 m have been encountered. The horizontal leg is designed to provide fractures in lengths of 91-152 m to permit 15 separate hydrofrack events. The injection of the fracking fluids provides enhanced permeability to coal beds, dense sands, and shale formations expected to have gas deposits. Millions of liters of these fluids are required for each well site's operation. The fluid composition may be toxic to aquatic biota. Surface water proximate to the well boring operations can become contaminated for the bore hole operations. Concern for the degradation of natural resources by these operations has been voiced by the scientific community and public. With these ecological concerns, it is possible to design the hydrofracking process to avoid lasting or injurious effects.This new source of natural gas is highly prized and with sufficient foresight the technology can be introduced as a clean means to sustainable energy production to meet the US energy needs.

Front Ecol Environ 2011; 9(9): 503-511.

\section{New journal}

The American Chemical Society recently launched the new journal ACS Sustainable Chemistry \& Engineering. The 
new publication is scheduled to offer the first articles online during the 4th quarter of 2012. The journal will focus on research topics minimizing environmental damage/harm and developing sustainable processes. Focal areas of research interest are life-cycle assessment, green chemistry, waste as a resource, alternative energy, and green innovative manufacturing. The journal will be organized to provide original peer-reviewed research output in the form of high-quality letters, research articles, feature articles, and perspectives or reviews. The journal will be available exclusively in electronic-only format which provides the author incentives of no fees for submission, color, page, or manuscript. Rapid publication is promised so that any accepted, unredacted manuscript will post online within $24 \mathrm{~h}$ of acceptance. http://pubs.acs.org/ journal/ascecg. 